\title{
Semen analysis: update on clinical value, current needs and future perspectives
}

\author{
Victoria Sánchez, Joachim Wistuba and Con Mallidis \\ Centre of Reproductive Medicine and Andrology, University Clinic Muenster, Domagkstrasse 11, D-48149 Muenster, \\ Germany \\ Correspondence should be addressed to C Mallidis; Email: con.mallidis@ukmuenster.de
}

\begin{abstract}
At present, evaluation of male reproductive function consists primarily of routine semen analysis, a collection of conventional microscopic assessments ideally performed following the guidelines set by the World Health Organization. While providing some insight into testicular function, these long-performed tests are limited in the information that they impart; more specifically, they are unable to predict true fertility potential. As a consequence, there is a need for the appraisal and consideration of newer semen parameters that may be more indicative of reproductive success. Although various novel assays have been introduced that broaden the scope of information available to both researcher and clinician, the utility of these tests remains limited due to the lack of standardisation of protocols and the absence of clinically established, dependable reference ranges. As such, it is not surprising that most of these parameters and their associated methods remain recommended for 'research purposes only'. With the burgeoning 'omics' revolution, nanotechnology and the development of new analytical instruments, there is now an opportunity for the identification and measurement of previously unknown features that may prove to be more indicative of each sperm's true functional status and capability. Once optimised, simplified, clinically validated and made more readily accessible, these new approaches hold the promise of forming the fulcrum upon which andrological investigations can enter a new era.
\end{abstract}

Reproduction (2013) 146 R249-R258

\section{Introduction}

Infertile couples undergo a series of investigations to provide insight into the cause(s) of the problem(s), aid in selecting the most appropriate action and give some indication to the probable outcome of their treatment. In males, such evaluation almost exclusively consists of routine semen analysis, the methods of which are unchanged for decades. One notable advance was the introduction of the standardised procedures of the first WHO manual. However, despite the need and importance of such guidelines, their use and worth have been and remain controversial, as evidenced by the ongoing debate (Cooper et al. 2010) of the new reference ranges (World Health Organization 2010).

Diagnostically, these long performed microscopic assessments do provide some indication of testicular and genital tract function. However, if an absolute dysfunction (e.g. azoospermia, necrospermia, asthenospermia and globozoospermia) is not found, they provide little information upon which a clinician can advise and act. This limitation is exemplified by the number of infertile men with 'normal' spermiograms who are euphemistically diagnosed with 'idiopathic' infertility. Prognostically, routine semen analysis is unable to either accurately gauge fertility potential or predict reproductive outcome. It is not surprising that only a small percentage of laboratories actually adhere to the WHO recommendations (Mallidis et al. 2012).

New approaches studying male reproductive function have been accompanied by the emergence of tools that are able to elucidate hitherto hidden features and hold the potential of revealing the real status of sperm function and fertility. Some have been included in the latter editions of the WHO manual as 'optional' or 'research' procedures. The purpose of this review is to examine the assortment of new methods and gauge their potential worth and use in clinical andrology.

\section{New ways of assessing old parameters}

In most laboratories, validity and dependability of semen analysis is reliant upon the skills and knowledge of the staff performing the assays. To increase precision, accuracy and reproducibility while eliminating human subjectivity, numerous semi-automated and fully automated computer-aided sperm analysis (CASA) systems have been developed. Early instruments measured motility, concentration and morphology but were unable 
to adequately distinguish sperm from debris (ESHRE 1998). Changes in design and the incorporation of different sample preparation protocols have improved accuracy and reliability; however, certain pitfalls remain. Motility and count can be sufficiently measured if samples are specifically prepared and the assessment's location is taken into account, but morphology evaluation is still prone to technical errors and inconsistencies (Garrett et al. 2003, Amann \& Katz 2004). Requiring similar standardisation and quality control as manual analysis, few laboratories use CASA routinely and then more as an adjunct than a replacement for established procedures.

A progression in automation is the miniaturised 'microfluidic' chip (Fig. 1) that counts spermatozoa based on variations in electrical impedance between two planar electrodes at a single frequency. Able to distinguish sperm, debris and round cells, a preliminary study found that concentrations calculated by the chip were comparable to conventional counts (Segerink et al. 2012). Presently limited to measuring concentration, pending further development, there is scope for motility and possibly morphology assessments. Still in its early developmental phase, this approach has potential; however, as examinations of the accuracy, precision and reliability have yet to be undertaken, the chip's true practicality and worth remain to be established. The true value of the chip, as that of the CASA instruments, will ultimately be revealed by the extent to which future

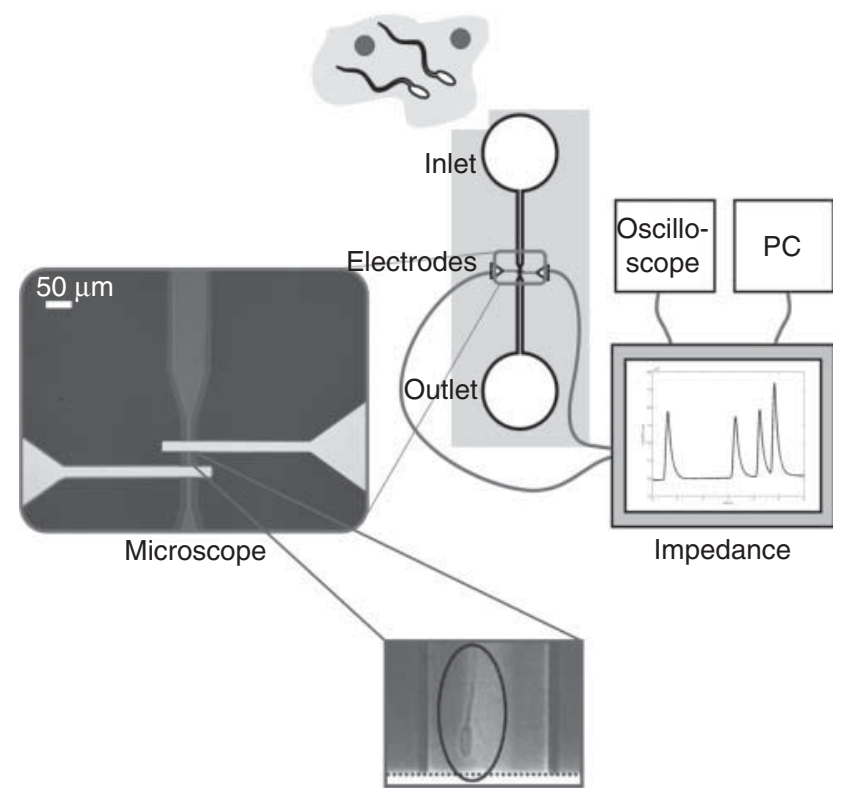

Figure 1 Schematic of the microfluidic semen analysis system showing the chip connected to an impedance analyser, which is in turn connected to a PC and an oscilloscope. Visualisation of the sample using a microscope shows a sperm approaching an electrode. (Segerink LI, Sprenkels AJ, Oosterhuis GJE, Vermes I \& van den Berg A 2012 Lab-on-a-chip technology for clinical diagnostics: the fertility chip. Ned Tijdschr Klin Chem Labgeneesk 37 61-63.) Reproduced by permission of The Royal Society of Chemistry. technological advances in microfluidics and imaging respectively are able to address the methods' current shortcomings.

\section{Sperm nuclear DNA}

The past decade has seen an increasing interest in sperm nuclear DNA (nDNA) due to its association with poor embryo development, low implantation rates and high miscarriage rates and possibly childhood illnesses (Simon et al. 2011). Two separate meta-analyses (Zini et al. 2008, Robinson et al. 2012) found that the outcomes of both IVF and ICSI were adversely affected when high numbers of sperm with DNA fragmentation were used. With similar results reported for intrauterine insemination (Bungum et al. 2004), assessment of sperm nDNA has been advocated as a predictor of Artificial Reproductive Techniques (ART) success. The situation is however not clear-cut, as numerous studies have also reported no correlation between damaged sperm nDNA and ART outcome (Bungum et al. 2007). Possible correlations between routine sperm parameters and nDNA damage are similarly indistinct, some studies reporting higher sperm DNA fragmentation index to be associated with oligozoospermia, asthenozoospermia, teratozoospermia, asthenoteratozoospermia and/or oligoasthenoteratozoospermia (Chi et al. 2011) while others report that sperm from 'normal' men were just as likely to contain fragmented nDNA (Simon et al. 2011).

\section{Methods}

Most sperm nDNA assessment procedures are based on the incorporation of metachromatic dyes (e.g. aniline blue, chromomycin and acridine orange; Fig. 2A), integration of labelled nucleotides (TUNEL assay; Fig. 2B) or differential movement of fragmented vs intact DNA (e.g. comet, sperm chromatin dispersion - SCD). Each test measures a different aspect and each has its limitations.

A flow cytometric version of the acridine orange test, the sperm chromatin structure assay (SCSA), measures DNA's susceptibility following acid treatment (Evenson et al. 2002). The most widely used and clinically applied method, SCSA, allows for the rapid assessment of thousands of cells providing a degree of statistical robustness; however, it measures propensity to damage rather than actual fragmentation (Makhlouf \& Niederberger 2006). Furthermore, it requires expensive equipment and specialised staff, thereby limiting its utility to large centres or out-service facilities.

TUNEL can be performed either flow cytometrically or as an immunocytochemical procedure and does measure actual damage (Makhlouf \& Niederberger 2006). However, it is dependent on the enzyme's unimpeded access to the entire DNA, it is affected by 

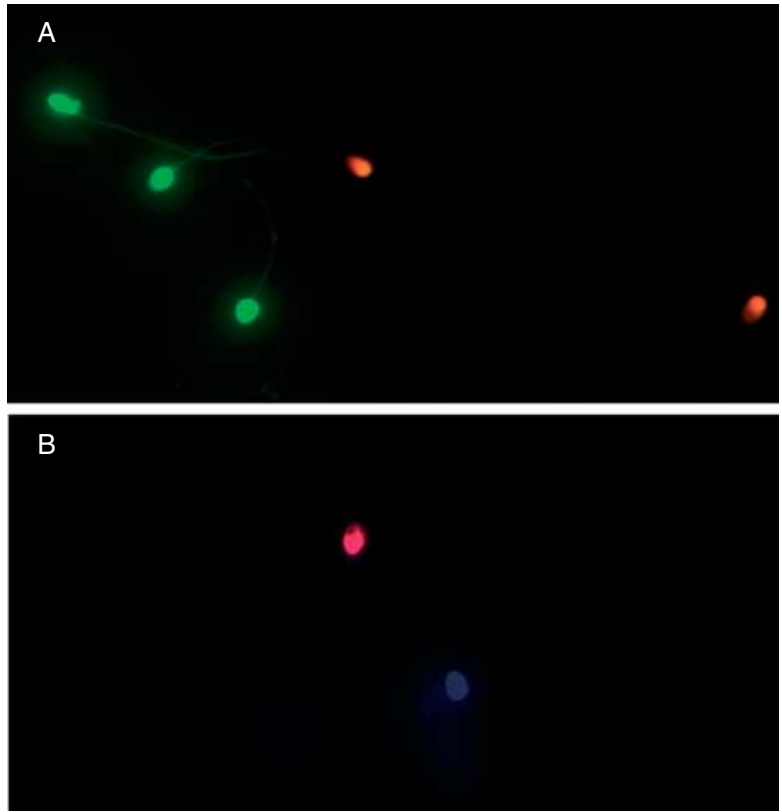

Figure 2 Sperm with intact/damaged nDNA as assessed by (A) acridine orange staining (green/orange) and (B) TUNEL (blue/red).

various procedural issues (e.g. fixative concentration, storage duration of fixed samples and fluorochrome type) and is influenced by cell viability and degree of DNA compaction (Mitchell et al. 2011), all of which resulted in several variations of the method and thus problems of standardisation and quality control (Evenson et al. 2007).

The comet and SCD assess migration of DNA following electrophoresis or acid treatment respectively. Although the appearance of the sperm nDNA after each procedure is similar, the results are garnered from opposite movements (i.e. a comet halo indicates damage while in SCD it equates to intact DNA). Depending on the lysis buffer's $\mathrm{pH}$, comet can detect single-strand breaks (alkaline), double-strand breaks (neutral (Chi et al. 2011)), both (two tailed), site-specific breaks (comet-FISH) and oxidative damage (comet-FPG (Moller 2006)). However, despite the introduction of commercial kits, few andrology laboratories use the method as accurate appraisal of the halos requires expensive image analysis, there is a lack of consensus on protocol standardisation and technical difficulties persist. SCD is inexpensive, quick, easy, available in kit form (i.e. Halosperm) (Fernandez et al. 2011) and measures DNA's propensity to damage. As with comet, little information exists on the sensitivity, reproducibility or specificity of SCD, which has raised questions on how accurately and reliably it measures fragmentation.

\section{Limitations}

Beyond each assay's specific foibles, all face the common impediments: absence of quality assurance, hence questions regarding the true levels of intra-assay and inter-laboratory variation; validation and wide variance in thresholds that indicate clinical significance, e.g. SCSA: $>20$ (Bungum et al. 2007) to $>30 \%$ (Evenson et al. 2002); TUNEL: $>12$ to $>36 \%$ (Tesarik et al. 2006); Comet: $\geq 14$ (Chi et al. 2011) to $>52 \%$ (Simon et al. 2011 ) and SCD: $>30 \%$ (N.B. threshold quoted in the manufacturer's instructions http://www.halotechdna. com/imgs/pdf/productos/halosperm/en/Clinical_Applications.pdf - accessed 13th February 2013) was derived using SCSA (Evenson et al. 2002). These concerns were echoed in the guidelines of the WHO (World Health Organization 2010), the practice committee of the American Society for Reproductive Medicine (Practice Committee of American Society for Reproductive Medicine 2008) and the European Society of Human Reproduction and Embryology's special interest group in andrology (Barratt et al. 2010). Despite the recent spirited challenge of these recommendations (Aitken et al. 2013a), which highlights the possible diagnostic benefits the use of these techniques may provide, the arguments put forward in the commentary for the inclusion of sperm nDNA testing in the routine investigation of male infertility fall short in allaying the aforementioned concerns, namely the practical shortcomings. Beyond any ambivalence surrounding diagnostic or prognostic value, the clinical utility of the methods is further handicapped in that, although they can provide valuable information, in most cases, sperm undergo harsh treatments that either destroy or render them unusable for any possible ART treatment.

\section{Oxidative stress}

In tandem with the interest in sperm nDNA fragmentation, has been the pursuit of the identification and possible treatment of the underlying cause(s) of the damage. Currently, the prevailing view is that deficient or defective DNA compaction leaves sperm chromatin susceptible to attack (Aitken et al. 2013b). An attack primarily mediated by reactive oxygen species (ROS), which are either excessively intracellularly/ extracellularly generated or are not kept in check by adequate antioxidant defences (Agarwal et al. 2008).

\section{Methods}

The numbers of available assays are as copious as the probes for the various ROS that have been shown to have some association with nDNA damage, their location and their actions. Among the more common are $\mathrm{H}_{2} \mathrm{O}_{2}$ (intracellular - NTB, DCFH-DA; extracellular - luminol); superoxide (intracellular - DHE, lucigenin; extracellular - cytochrome $c$; mitochondrial - MitoSOX); nitric oxide (DAF-DA); peroxynitrite (dihydrorhodamine 123) and lipid peroxidation (thiobarbituric acid) 
(Agarwal et al. 2008, Aziz et al. 2010, Aitken et al. 2013b). A similar plethora exists for antioxidants such as superoxide dismutase, vitamins (C, E and A), catalase, glutathione (peroxidase and reductase) as well as total antioxidant capacity. To make some clinical sense of the findings, a scoring system involving both ROS and antioxidant levels has been suggested and reference values proposed (Agarwal et al. 2008).

These assays can provide useful information for research (e.g. the propensity of sperm to generate ROS following redox stimulation); however, their clinical efficacy is debatable as what is precisely measured by the probes is still open to question (World Health Organization 2010) and the assays, especially those based on chemiluminescence, are beset by numerous serious confounders (Aitken et al. 2004) which limit their practicality.

\section{Treatments}

To counteract the deleterious actions of oxidative stress, a variety of oral antioxidants (e.g. vitamin C, vitamin E, glutathione, zinc, L-carnitine and $\mathrm{N}$-acetyl cysteine) have been suggested as means of improving sperm quality and preserving nDNA integrity. However, despite the presence in the market of various supplements, the data supporting their beneficial qualities is at best speculative, as the few studies that have been conducted comprise low patient numbers, have disparities in experimental design, differing types, doses, duration of treatment and end points. Until more substantive studies are conducted, their true efficacy remains unknown.

\section{The 'omics' revolution}

Merging two rapidly advancing disciplines, molecular biology and bioinformatics, has resulted in a multitude of sophisticated techniques that have significantly broadened the scope of biomedical research. The sheer quality and quantity of information now available provides tantalising opportunities but also presents some serious challenges.

\section{Transcriptomics}

As detailed global gene expression profiling has been successfully used to diagnose various diseases, it was inevitable that this approach would be adopted to obtain information on the molecular mechanisms affecting spermatogenesis and possibly identify hallmarks for the diagnosis of male infertility.

Until recently, information from testicular biopsies was primarily histological descriptions of spermatogenic activity and immunohistochemical localisations of certain marker proteins. One of the first studies to utilise nucleic acid arrays to evaluate testicular tissue found that men with different infertility phenotypes had perturbations in the expression of genes involved in germ cell development (e.g. DAZ, DAZL, TSTAR, TSPY and CDC25C) (Fox et al. 2003). Another comparing testicular material from humans and mouse models of infertility found that although differential expression was seen in numerous genes, some of known importance to spermatogenesis (e.g. mice: Prlr, Tmsb4x, Zfp37; humans: S100A10, SOX9 and SRY), there was little consistency or agreement across species (Rockett et al. 2004). A different approach, focussing on the RAS oncogene RAP1A as a possible specific marker for fertility (Yang et al. 2004), found that although mRNA expression was higher in azoospermic compared with normozoospermic patients, this was accompanied by variations in 127 other genes. A similar outcome was reported by Ellis et al. (2007) in different human infertility phenotypes, namely distinct expression patterns, some germ cell-specific, but large variations in numerous genes of 'unknown' function. (A partial list of identified genes shown to have some relevance to male reproductive function is provided in Supplementary Table 1, see section on supplementary data given at the end of this article.)

\section{Limitations}

The main impedances of this approach are the large number of genes expressed during spermatogenesis (i.e. $>4 \%$ of the human genome), our limited knowledge of the transcriptional mechanisms of sperm development and nurture and the variety of cells present in the testis, each with a specific role, function and RNA expression pattern. This latter intricacy was clearly illustrated in a study of patients with various forms of spermatogenic arrest which found that men with Sertoli cell-only syndrome, hence with somatic cells alone, there were significant variations in the expression of 188 genes, most of unknown function (Spiess et al. 2007).

\section{Sperm mRNA}

Circumventing the difficulties related to testicular material, spermatozoal RNA presents itself as an attractive alternative. As sperm are transcriptionally inert, the proposition of assessing RNA expression at first appears oxymoronic; however, numerous studies have now shown that sperm contain a complex mRNA population with the quantity of each transcript mirroring expression throughout the sperms' development (Miller et al. 1999). As such, sperm RNA profiles have been evaluated in samples with abnormal motility (Wang et al. 2004), from diabetic (Mallidis et al. 2009a, 2009b) and infertile men (Garrido et al. 2009). Still contentious, the findings of these studies point to the potential of the technique (Platts et al. 2007); however, as with testicular RNA, the quantity of information, its relevance and the 
large gaps in our knowledge, all handicap its utility. Furthermore, the entire sample needs to be pooled to provide sufficient material for analysis (Garrido et al. 2009), stringent validation is needed to ensure the RNA's quality and origin (Platts et al. 2007), the expense and assortment of equipment, microarrays, and the specialised skills required all consign the method, for the time being, suitable for research only. (A partial list of identified genes is provided in Supplementary Table 1.)

\section{Epigenomics}

The heritable changes in gene expression due to variations in DNA methylation and histone posttranslational modifications, epigenetic regulation is a physiological occurrence in all cells, most prominently in developing germ cells.

\section{Methylation}

The silencing or expression of certain maternally or paternally inherited alleles is achieved by 'genomic imprinting', a process primarily involving methylation of cytosine in the genes' CpG islands. Normally erased during foetal life, these modifications are re-established during gametogenesis with some methylation patterns varying throughout spermatogenesis. The failure of DNA re-methylation is implicated in aberrant foetal development and disorders such as Angelman's and Beckwith-Wiedemann's syndromes. There have been concerns that such conditions may result from ART procedures, as animal studies found more imprinting errors in ART than in naturally conceived offspring (Maher 2005). A contrasting view is that the errors are not due to the ART procedure per se but rather that gametes from infertile subjects may carry increased epigenomic abnormalities (Hammoud et al. 2011). As the issue remains unresolved, the study of epigenetic patterns and their association with male infertility has gained increasing impetus.

Among the first profiles to be associated with abnormal spermatogenesis, defective methylation of the maternally inherited $\mathrm{H} 19$ gene was found in oligozoospermic patients (Marques et al. 2004). This, with findings of a later study, led to the suggestion that patients with a sperm concentration below 10 million/ml were likely to have epigenetic abnormalities in $\mathrm{H} 19$ and the paternally inherited MEST gene (Marques et al. 2008). Another study focussing on IGF2 and H19 found that compared with samples from normozoospermic men, sperm from patients with teratozoospermia and oligoasthenoteratozoospermia contained significantly lower levels of methylation.

As these anomalous methylation patterns were closely correlated with sperm concentration, they have been proposed as possible biomarkers of defective spermatogenesis. A proposition given further credence, and expanded upon by Poplinski et al. (2010), suggests that as well as samples from patients with low sperm count, those with abnormal motility and morphology also contained hypermethylation of MEST and hypomethylation of a IGF2/H19 imprinting control region. Interestingly, aberrant methylation of $\mathrm{H} 19$ has been shown not only in testicular and epididymal dysfunction but also in cases of genital tract blockage whether endogenous (i.e. obstructive azoospermia) or iatrogenic (i.e. vasectomy) (Minor et al. 2011).

Associations with abnormal semen quality have also been found in non-imprinted genes such as CREM, whose level of methylation was found to be negatively correlated with sperm concentration, motility, morphology and significantly higher in patients with aberrant protamination and oligozoospermia (Nanassy \& Carrell 2011). Similarly, DAZL, the Y chromosome gene associated with spermatogenic arrest, showed high levels of methylation in sperm from oligoasthenoteratozoospermia patients (Navarro-Costa et al. 2010) while hypermethylation of the promoter region of methylenetetrahydrofolate reductase, the rate limiting enzyme of the methyl cycle, has been allied to idiopathic infertility (Wu et al. 2010) and non-obstructive azoospermia (Khazamipour et al. 2009). (Descriptions of the proposed functions of the referred to genes are provided in Supplementary Table 1.)

\section{Histone modifications}

A multitude of post-translational histone modifications has recently been described (e.g. methylation, acetylation, ubiquitylation and phosphorylation), the majority of whose functions remain unknown. Methylation, which varies in number and location of the added moieties, is associated with gene silencing but dependent on which residue is methylated can also lead to expression, a dual capability also seen with phosphorylation and ubiquitylation.

The acetylation/deacetylation of lysine residues in histones 3 and 4 (H3K9ac, 12-H4K12ac) has been suggested to not only affect male fertility but may also have a negative impact on the development of the early embryo (Paradowska et al. 2012). As both are prominent in the male pronucleus, these modifications may provide insights into the paternal contribution to the gene expression of both zygote and developing embryo.

Recent discoveries have opened more vistas into epigenetic regulation of germ cell development in the form of the various small RNAs such as microRNAs, endogenous small interfering RNAs and PIWI-interacting RNAs. What role these small non-coding molecules play, how influential they are to male reproductive function and how they might contribute to clinical practice are yet to be deciphered. 


\section{Limitations}

Our understanding of the role and importance of epigenetic regulation is still in its infancy and as such its utility to clinical andrology is limited. Beyond the substantial gaps in our knowledge and the growing list of potentially influential genes, another hindrance is that regardless of the method (e.g. bisulphite conversion, immunochemical detection, PCR, immunoprecipitation and promoter analysis) the results constitute an average of the profiles of a large sperm population. This inability to discriminate the profile and status of each individual cell necessitates the assumption that the sperm population is epigenetically homogeneous. If, however, as in so many other aspects of spermatogenesis, epigenetic regulation is heterogeneous, then any abnormalities present may either mask or be masked by normal sperm.

\section{Proteomics}

Among the earliest analyses, the presence/absence and quantity/quality of a wide variety of proteins found in semen and sperm have been evaluated with the goal of finding diagnostic and/or prognostic indicators of reproductive function. The number of proteins identified and characterised in recent years mirrors the speed of development and the increasing analytical power of modern techniques.

While most early candidates were found not to be clinically useful, new contenders appear regularly such as protamines 1 and 2 (P1 and P2). Beyond fundamental elements of sperm chromatin structure, these small proteins are also involved in numerous mechanisms essential for correct sperm function. It is not then surprising that aberrant $\mathrm{P} 1$ :P2 ratios have been associated with infertility and ART outcome, both at the mRNA and protein (Hammadeh et al. 2010) levels. Although informative, clinically the use of this ratio is limited, as with previously mentioned strategies, by the necessity to pool the entire sample and extraction procedures that render the sample unusable for ART.

With quicker, more precise means for separation, resolution and detection, investigations are no longer restricted to single or small numbers of proteins but can encompass the gamut of compounds present in sperm and the ejaculate. This has led to an inventory numbering in the thousands and proteomic profiles characterising, among others, sperm maturation (Baker et al. 2013), infertility (Govindaraju et al. 2012), varicocele (Zylbersztejn et al. 2013) and ART outcome (Pixton et al. 2004). The growing sophistication of techniques (e.g. MALDI-TOF MS) has extended the scope of investigations so that 2-D reference maps, subcompartmental analysis (i.e. head and flagella (Baker et al. 2013)) and the assessment of specific posttranslational modifications are now possible. However, the sheer quantity of information, the complexity of the compositions, the number of isolated proteins with unknown actions/functions and the destructive nature of the techniques restrict their use to research purposes only. (A partial list of identified proteins is provided in Supplementary Table 2, see section on supplementary data given at the end of this article.)

\section{Metabolomics}

As intermediate products of metabolism are the consequence of a cell's physiology, their identification and measurement can serve as a biomarker of the cellular processes operating at a particular time and under specific conditions. Analogous to the transcriptome and proteome, the metabolome is considered to be of higher sensitivity as more changes occur in these small molecules than during post-transcriptional and posttranslational events. The monitoring of these compounds requires an array of sophisticated techniques (e.g. HPLC, mass spectroscopy and NMR) followed by advanced bioinformatic analysis for the apposite processing of the data. Such approaches have been employed to investigate toxicological effects (van Ravenzwaay et al. 2012) and the influence of diabetes (Mallidis et al. 2009a, 2009b) on testicular function, abnormal spermatogenesis (Aaronson et al. 2010) and seminal plasma from fertile and infertile men (Gupta et al. 2011). (A partial list of identified metabolites is provided in Supplementary Table 3, see section on supplementary data given at the end of this article.)

Vibrational spectroscopic methods (i.e. Fourier transform infrared and near-infrared) have been developed, which hold the potential of assessing the metabolome without causing damage with some encouraging preliminary studies performed to evaluate oocyte and embryo quality and viability; however, how these approaches can be applied to the analysis and selection of sperm remains to be seen.

\section{Non-invasive therapeutic approaches and future perspectives}

The challenge facing andrology has and will be the development of a method that, without damaging or compromising integrity and function, assesses, selects and provides for use a single living sperm able to produce a normal pregnancy and ultimately a healthy child. It is unrealistic that any method be able to encompass on all the aspects of sperm structure detailed in the preceding sections of this review. However, a procedure that could augment traditional semen analysis providing broad information on fertility potential, while making available a sperm that could be safely used for ART, would be a significant advance.

Touted as the most important functional feature for predicting reproductive outcome, sperm nDNA integrity 
appears to be the most promising candidate for inclusion in any prospective non-destructive sperm assessment/ selection method. As such, almost all new techniques provide some form of evaluation/association indicating how successful the procedure is in also identifying sperm with intact nDNA.

\section{Microscopy}

Motile Sperm Organelle Morphological Examination (MSOME) and polscopy assess and select sperm based on differing aspects of morphological 'normalcy', which are also claimed to reflect nDNA status. MSOME utilises highmagnification Normarski optics to detect nuclear vacuoles, which are considered to be indicative of abnormal sperm chromatin and nDNA fragmentation (Hammoud et al. 2012). However, there are conflicting findings regarding any such association (Cassuto et al. 2012).

Polscopy assesses birefringence (i.e. the refractive index based on polarisation and direction propagated light) relating sperm head density to maturity, health and nDNA integrity (Ghosh et al. 2012). Some support for this concept has been provided; however, as with MSOME, the technique's validity is yet to be established as few groups employ the method and even fewer studies have examined its clinical performance.

\section{Binding}

Separation of healthy/mature or damaged/immature sperm by their ability/inability to bind certain substances presents an attractive option as potentially it neither interferes with structure nor endangers integrity. Additionally, numerous techniques can be used (i.e. flow cytometry, magnetic activated cell sorting and coated glass wool filtration), sperm remain alive and thus available for ART. Numerous such compounds have been proposed; hyaluronic acid (HA) is a major component of the cumulus for which only mature sperm possess a receptor. As mature sperm have intact nDNA, the HA-bound fraction must be enriched with sperm possessing high nDNA integrity. While some evidence for this assertion exists (Yagci et al. 2010), the clinical value of the assay remains limited due to the lack of correlations between HA binding and parameters of reproductive outcome, specifically those associated with sperm nDNA integrity (i.e. embryo quality, implantation and clinical pregnancy) (Nijs et al. 2010). A parallel approach, zona pellucida binding (Liu et al. 2011), requires neither intervention nor treatment and is closer to 'natural' conditions, as only sperm attached to the 'physiological' site of sperm-oocyte binding are collected. Beyond the serious practical constraint of access to and availability of suitable zonae, neither the nDNA status of the sperm nor the clinical outcome of their use has been established.
Various compounds that bind damaged sperm have also been suggested, such as apoptotic markers Annexin V, Yo Pro 1 and the oligopeptide p53, which has high affinity for disrupted DNA and is capable of binding single- and double-strand DNA breaks (Enciso et al. 2012). As with the microscopic methods, these compounds may improve the quality of sperm available for ART; however, as their use constitutes a sorting that decreases the number of nDNA-damaged sperm but does not assure that all isolated sperm possess intact nDNA, their benefit to ART remains somewhat restricted. A limitation is also shared by swim up, density centrifugation and separation
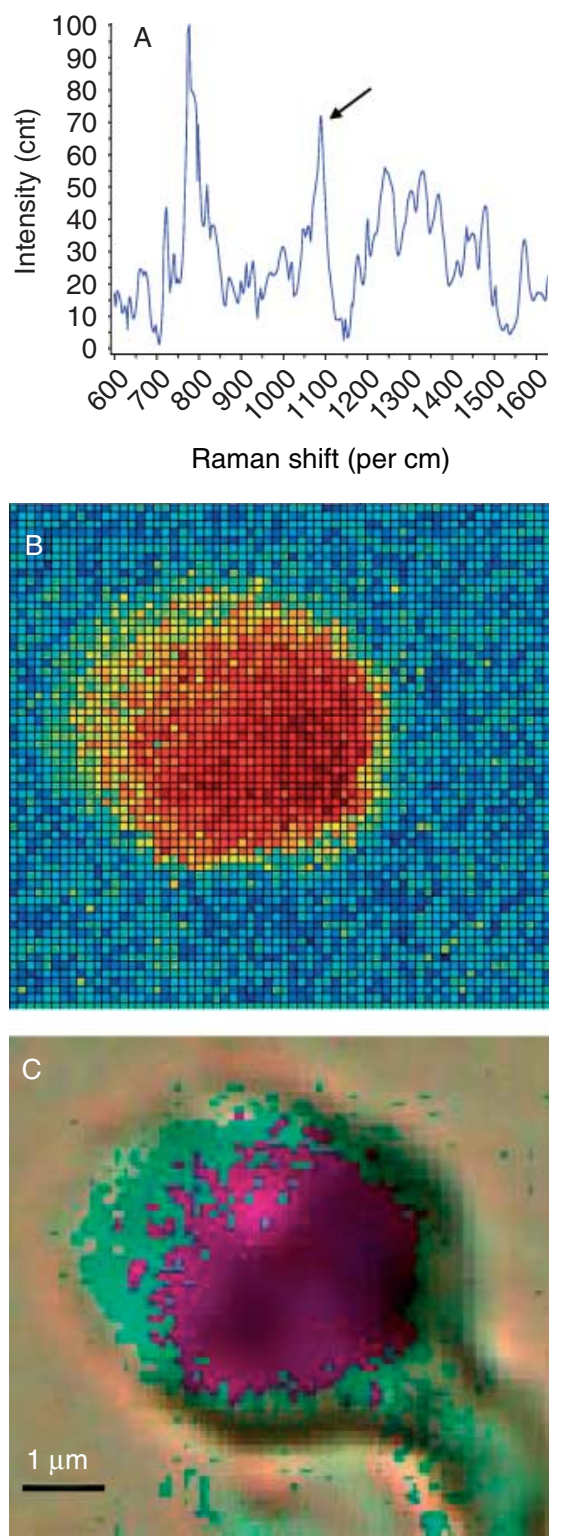

Figure 3 Raman spectra (A) showing the peak associated with the DNA backbone (arrow) can be taken every $50 \mathrm{~nm}$ across a sperm head allowing for the construction of a map detailing the status of the DNA (B) and by superimposition of the in situ localisation of the damage $(C)$. 
procedures based on electric charge (e.g. Z potential and electrophoretic sorting).

\section{Raman microspectroscopy}

A method that does provide a molecular 'fingerprint' of a specific cell's content, non-invasively and nondestructively, Raman microspectroscopy is based on the inelastic scattering of light and has been successfully used to assess the function of a variety of cells while not affecting their viability. Initial investigations showed the potential of the technique to identify the chemical signatures underlying morphology, motility and mitochondrial status of human sperm (Huser et al. 2009, Meister et al. 2010). In our own studies, we extended the utility and information garnered by the technique to the extent where nDNA damage resulting from various causes (i.e. UVb irradiation (Mallidis et al. 2011)), oxidative stress and endogenous factors (Sanchez et al. 2012; Fig. 3) can be determined, localised and mapped in situ. Although early in the verification process, thus far the results are encouraging and augur well that the method may circumvent many of the problems of the other techniques. However, for its full potential to be realised, it must undergo the same stringent appraisal and clinical validation as all other proposed techniques.

\section{Conclusions}

The recent advances in technology, coupled with our growing understanding of male reproductive function, form the basis upon which new diagnostic and prognostic parameters may be identified and assessed once/if their clinical significance can be proven. That said, most of the current 'new' approaches are, and in all probability will remain, of limited clinical use as the methods they involve, the information they provide and the gaps in our knowledge are such that for the foreseeable future at least, they will stay consigned to the realm of research. Of the newer developments, 'lab on chip' nanotechnology and Raman microspectroscopy appear to have more immediate potential for the analysis, separation, characterisation and selection (respectively) of living sperm. As tantalising as this thought may be, for the present, the utility of these methods awaits verification and validation.

\section{Supplementary data}

This is linked to the online version of the paper at http://dx.doi. org/10.1530/REP-13-0109.

\section{Declaration of interest}

The authors declare that there is no conflict of interest that could be perceived as prejudicing the impartiality of the review.

\section{Funding}

This research did not receive any specific grant from any funding agency in the public, commercial or not-for-profit sector.

\section{Acknowledgements}

The authors thank Dr L Segerink and The Royal Society of Chemistry for their permission to use and modify their figures.

\section{References}

Aaronson DS, Iman R, Walsh TJ, Kurhanewicz J \& Turek PJ 2010 A novel application of $1 \mathrm{H}$ magnetic resonance spectroscopy: non-invasive identification of spermatogenesis in men with non-obstructive azoospermia. Human Reproduction 25 847-852. (doi:10.1093/humrep/ dep475)

Agarwal A, Cocuzza M, Abdelrazik H \& Sharma RK 2008 Oxidative stress measurement in patients with male or female factor infertility. In Handbook of Chemiluminescent Methods in Oxidative Stress Assessment, pp 195-218. Eds I Popov \& G Lewin. Kerala, India: Transworld Research Network.

Aitken RJ, Baker MA \& O'Bryan M 2004 Shedding light on chemiluminescence: the application of chemiluminescence in diagnostic andrology. Journal of Andrology 25 455-465. (doi:10.1002/j.1939-4640. 2004.tb02815.x)

Aitken RJ, Bronson R, Smith TB \& De Iuliis GN 2013a The source and significance of DNA damage in human spermatozoa; a commentary on diagnostic strategies and straw man fallacies. Molecular Human Reproduction 19 475-485. (doi:10.1093/molehr/gat025)

Aitken RJ, Smith TB, Lord T, Kuczera L, Koppers AJ, Naumovski N, Connaughton H, Baker MA \& De luliis GN 2013b On methods for the detection of reactive oxygen species generation by human spermatozoa: analysis of the cellular responses to catechol oestrogen, lipid aldehyde, menadione and arachidonic acid. Andrology 1 192-205. (doi:10.1111/j. 2047-2927.2012.00056.x)

Amann RP \& Katz DF 2004 Reflections on CASA after 25 years. Journal of Andrology 25 317-325. (doi:10.1002/j.1939-4640.2004.tb02793.x)

Aziz N, Novotny J, Oborna I, Fingerova H, Brezinova J \& Svobodova M 2010 Comparison of chemiluminescence and flow cytometry in the estimation of reactive oxygen and nitrogen species in human semen. Fertility and Sterility 94 2604-2608. (doi:10.1016/j.fertnstert.2010.03. 022)

Baker MA, Naumovski N, Hetherington L, Weinberg A, Velkov T \& Aitken RJ 2013 Head and flagella subcompartmental proteomic analysis of human spermatozoa. Proteomics 13 61-74. (doi:10.1002/pmic. 201200350)

Barratt CL, Aitken RJ, Bjorndahl L, Carrell DT, de Boer P, Kvist U, Lewis SE, Perreault SD, Perry MJ, Ramos L et al. 2010 Sperm DNA: organization, protection and vulnerability: from basic science to clinical applications a position report. Human Reproduction 25 824-838. (doi:10.1093/ humrep/dep465)

Bungum M, Humaidan P, Spano M, Jepson K, Bungum L \& Giwercman A 2004 The predictive value of sperm chromatin structure assay (SCSA) parameters for the outcome of intrauterine insemination, IVF and ICSI. Human Reproduction 19 1401-1408. (doi:10.1093/humrep/deh280)

Bungum M, Humaidan P, Axmon A, Spano M, Bungum L, Erenpreiss J \& Giwercman A 2007 Sperm DNA integrity assessment in prediction of assisted reproduction technology outcome. Human Reproduction 22 174-179. (doi:10.1093/humrep/del326)

Cassuto NG, Hazout A, Hammoud I, Balet R, Bouret D, Barak Y, Jellad S, Plouchart JM, Selva J \& Yazbeck C 2012 Correlation between DNA defect and sperm-head morphology. Reproductive BioMedicine Online 24 211-218. (doi:10.1016/j.rbmo.2011.10.006)

Chi HJ, Chung DY, Choi SY, Kim JH, Kim GY, Lee JS, Lee HS, Kim MH \& Roh SI 2011 Integrity of human sperm DNA assessed by the neutral comet assay and its relationship to semen parameters and clinical outcomes for the IVF-ET program. Clinical and Experimental Reproductive Medicine 38 10-17. (doi:10.5653/cerm.2011.38.1.10) 
Cooper TG, Noonan E, von Eckardstein S, Auger J, Baker HW, Behre HM, Haugen TB, Kruger T, Wang C, Mbizvo MT et al. 2010 World Health Organization reference values for human semen characteristics. Human Reproduction Update 16 231-245. (doi:10.1093/humupd/dmp048)

Ellis PJ, Furlong RA, Conner SJ, Kirkman-Brown J, Afnan M, Barratt C, Griffin DK \& Affara NA 2007 Coordinated transcriptional regulation patterns associated with infertility phenotypes in men. Journal of Medical Genetics 44 498-508. (doi:10.1136/jmg.2007.049650)

Enciso M, Pieczenik G, Cohen J \& Wells D 2012 Development of a novel synthetic oligopeptide for the detection of DNA damage in human spermatozoa. Human Reproduction 27 2254-2266. (doi:10.1093/ humrep/des201)

ESHRE 1998 Guidelines on the application of CASA technology in the analysis of spermatozoa. ESHRE Andrology Special Interest Group. European Society for Human Reproduction and Embryology. Human Reproduction 13 142-145. (doi:10.1093/humrep/13.1.142)

Evenson DP, Larson KL \& Jost LK 2002 Sperm chromatin structure assay: its clinical use for detecting sperm DNA fragmentation in male infertility and comparisons with other techniques. Journal of Andrology 23 25-43. (doi:10.1002/j.1939-4640.2002.tb02599.x)

Evenson DP, Kasperson K \& Wixon RL 2007 Analysis of sperm DNA fragmentation using flow cytometry and other techniques. Society of Reproduction and Fertility Supplement 65 93-113.

Fernandez JL, Cajigal D, Lopez-Fernandez C \& Gosalvez J 2011 Assessing sperm DNA fragmentation with the sperm chromatin dispersion test. Methods in Molecular Biology 682 291-301. (doi:10.1007/978-160327-409-8_21)

Fox MS, Ares VX, Turek PJ, Haqq C \& Reijo Pera RA 2003 Feasibility of global gene expression analysis in testicular biopsies from infertile men. Molecular Reproduction and Development 66 403-421. (doi:10.1002/ mrd.10364)

Garrett C, Liu DY, Clarke GN, Rushford DD \& Baker HW 2003 Automated semen analysis: 'zona pellucida preferred' sperm morphometry and straight-line velocity are related to pregnancy rate in subfertile couples. Human Reproduction 18 1643-1649. (doi:10.1093/humrep/deg306)

Garrido N, Martinez-Conejero JA, Jauregui J, Horcajadas JA, Simon C, Remohi J \& Meseguer M 2009 Microarray analysis in sperm from fertile and infertile men without basic sperm analysis abnormalities reveals a significantly different transcriptome. Fertility and Sterility 91 1307-1310. (doi:10.1016/j.fertnstert.2008.01.078)

Ghosh S, Chattopadhyay R, Bose G, Ganesh A, Das S \& Chakravarty BN 2012 Selection of birefringent spermatozoa under Polscope: effect on intracytoplasmic sperm injection outcome. Andrologia 44 (Suppl 1) 734-738. (doi:10.1111/j.1439-0272.2011.01258.x)

Govindaraju A, Dogan S, Rodriguez-Osorio N, Grant K, Kaya A \& Memili E 2012 Delivering value from sperm proteomics for fertility. Cell and Tissue Research 349 783-793. (doi:10.1007/s00441-012-1452-2)

Gupta A, Mahdi AA, Ahmad MK, Shukla KK, Jaiswer SP \& Shankhwar SN 2011 1H NMR spectroscopic studies on human seminal plasma: a probative discriminant function analysis classification model. Journal of Pharmaceutical and Biomedical Analysis 54 106-113. (doi:10.1016/ j.jpba.2010.07.021)

Hammadeh ME, Hamad MF, Montenarh M \& Fischer-Hammadeh C 2010 Protamine contents and P1/P2 ratio in human spermatozoa from smokers and non-smokers. Human Reproduction 25 2708-2720. (doi:10.1093/ humrep/deq226)

Hammoud SS, Nix DA, Hammoud AO, Gibson M, Cairns BR \& Carrell DT 2011 Genome-wide analysis identifies changes in histone retention and epigenetic modifications at developmental and imprinted gene loci in the sperm of infertile men. Human Reproduction 26 2558-2569. (doi:10.1093/humrep/der192)

Hammoud I, Boitrelle F, Ferfouri F, Vialard F, Bergere M, Wainer B, Bailly M, Albert M \& Selva J 2013 Selection of normal spermatozoa with a vacuole-free head $(\times 6300)$ improves selection of spermatozoa with intact DNA in patients with high sperm DNA fragmentation rates. Andrologia 45 163-170. (doi:10.1111/j.1439-0272.2012.01328.x)

Huser T, Orme CA, Hollars CW, Corzett MH \& Balhorn R 2009 Raman spectroscopy of DNA packaging in individual human sperm cells distinguishes normal from abnormal cells. Journal of Biophotonics 2 322-332. (doi:10.1002/jbio.200910012)
Khazamipour N, Noruzinia M, Fatehmanesh P, Keyhanee M \& Pujol P 2009 MTHFR promoter hypermethylation in testicular biopsies of patients with non-obstructive azoospermia: the role of epigenetics in male infertility. Human Reproduction 24 2361-2364. (doi:10.1093/humrep/dep194)

Liu N, Zhang Z, Li Y, Liu D, Chen X \& Yao Z 2011 Sperm-oocyte interaction and in vitro fertilization clinical outcomes in patients with unexplained infertility. Journal of Central South University. Medical Sciences 36 439-447. (doi:10.3969/j.issn.1672-7347.2011.05.012)

Maher ER 2005 Imprinting and assisted reproductive technology. Human Molecular Genetics 14 R133-R138. (doi:10.1093/hmg/ddi107)

Makhlouf AA \& Niederberger C 2006 DNA integrity tests in clinical practice: it is not a simple matter of black and white (or red and green). Journal of Andrology 27 316-323. (doi:10.2164/jandrol.05217)

Mallidis C, Agbaje I, O'Neill J \& McClure N 2009a The influence of type 1 diabetes mellitus on spermatogenic gene expression. Fertility and Sterility 92 2085-2087. (doi:10.1016/j.fertnstert.2009.06.006)

Mallidis C, Green BD, Rogers D, Agbaje IM, Hollis J, Migaud M, Amigues E, McClure N \& Browne RA 2009b Metabolic profile changes in the testes of mice with streptozotocin-induced type 1 diabetes mellitus. International Journal of Andrology 32 156-165. (doi:10.1111/j.1365-2605. 2007.00829.x)

Mallidis C, Wistuba J, Bleisteiner B, Damm OS, Gross P, Wubbeling F, Fallnich C, Burger M \& Schlatt S 2011 In situ visualization of damaged DNA in human sperm by Raman microspectroscopy. Human Reproduction 26 1641-1649. (doi:10.1093/humrep/der122)

Mallidis C, Cooper TG, Hellenkemper B, Lablans M, Uckert F \& Nieschlag E 2012 Ten years' experience with an external quality control program for semen analysis. Fertility and Sterility 98 611-616.e4. (doi:10.1016/j.fertnstert.2012.05.006)

Marques CJ, Carvalho F, Sousa M \& Barros A 2004 Genomic imprinting in disruptive spermatogenesis. Lancet 363 1700-1702. (doi:10.1016/ S0140-6736(04)16256-9)

Marques CJ, Costa P, Vaz B, Carvalho F, Fernandes S, Barros A \& Sousa M 2008 Abnormal methylation of imprinted genes in human sperm is associated with oligozoospermia. Molecular Human Reproduction $\mathbf{1 4}$ 67-74. (doi:10.1093/molehr/gam093)

Meister K, Schmidt DA, Brundermann E \& Havenith M 2010 Confocal Raman microspectroscopy as an analytical tool to assess the mitochondrial status in human spermatozoa. Analyst 135 1370-1374. (doi:10.1039/b927012d)

Miller D, Briggs D, Snowden H, Hamlington J, Rollinson S, Lilford R \& Krawetz SA 1999 A complex population of RNAs exists in human ejaculate spermatozoa: implications for understanding molecular aspects of spermiogenesis. Gene 237 385-392. (doi:10.1016/S03781119(99)00324-8)

Minor A, Chow V \& Ma S 2011 Aberrant DNA methylation at imprinted genes in testicular sperm retrieved from men with obstructive azoospermia and undergoing vasectomy reversal. Reproduction $\mathbf{1 4 1}$ 749-757. (doi:10.1530/REP-11-0008)

Mitchell LA, De Iuliis GN \& Aitken RJ 2011 The TUNEL assay consistently underestimates DNA damage in human spermatozoa and is influenced by DNA compaction and cell vitality: development of an improved methodology. International Journal of Andrology 34 2-13. (doi:10.1111/ j.1365-2605.2009.01042.x)

Moller P 2006 The alkaline comet assay: towards validation in biomonitoring of DNA damaging exposures. Basic Clinical Pharmacology and Toxicology 98 336-345. (doi:10.1111/j.1742-7843.2006. pto_167.x)

Nanassy L \& Carrell DT 2011 Abnormal methylation of the promoter of CREM is broadly associated with male factor infertility and poor sperm quality but is improved in sperm selected by density gradient centrifugation. Fertility and Sterility 95 2310-2314. (doi:10.1016/ j.fertnstert.2011.03.096)

Navarro-Costa P, Nogueira P, Carvalho M, Leal F, Cordeiro I, CalhazJorge C, Goncalves J \& Plancha CE 2010 Incorrect DNA methylation of the DAZL promoter CpG island associates with defective human sperm. Human Reproduction 25 2647-2654. (doi:10.1093/humrep/deq200)

Nijs M, Creemers E, Cox A, Janssen M, Vanheusden E, Van der Elst J \& Ombelet W 2010 Relationship between hyaluronic acid binding assay and outcome in ART: a pilot study. Andrologia 42 291-296. (doi:10.1111/j.1439-0272.2009.00992.x) 
Paradowska AS, Miller D, Spiess AN, Vieweg M, Cerna M, DvorakovaHortova K, Bartkuhn M, Schuppe HC, Weidner W \& Steger K 2012 Genome wide identification of promoter binding sites for H4K12ac in human sperm and its relevance for early embryonic development. Epigenetics 7 1057-1070. (doi:10.4161/epi.21556)

Pixton KL, Deeks ED, Flesch FM, Moseley FL, Bjorndahl L, Ashton PR, Barratt CL \& Brewis IA 2004 Sperm proteome mapping of a patient who experienced failed fertilization at IVF reveals altered expression of at least 20 proteins compared with fertile donors: case report. Human Reproduction 19 1438-1447. (doi:10.1093/humrep/deh224)

Platts AE, Dix DJ, Chemes HE, Thompson KE, Goodrich R, Rockett JC, Rawe VY, Quintana S, Diamond MP, Strader LF et al. 2007 Success and failure in human spermatogenesis as revealed by teratozoospermic RNAs. Human Molecular Genetics 16 763-773. (doi:10.1093/hmg/ ddm012)

Poplinski A, Tuttelmann F, Kanber D, Horsthemke B \& Gromoll J 2010 Idiopathic male infertility is strongly associated with aberrant methylation of MEST and IGF2/H19 ICR1. International Journal of Andrology 33 642-649. (doi:10.1111/j.1365-2605.2009.01000.x)

Practice Committee of American Society for Reproductive Medicine 2008 The clinical utility of sperm DNA integrity testing. Fertility and Sterility $\mathbf{9 0}$ S178-S180. (doi:10.1016/j.fertnstert.2008.08.054)

van Ravenzwaay B, Herold M, Kamp H, Kapp MD, Fabian E, Looser R, Krennrich G, Mellert W, Prokoudine A, Strauss V et al. 2012 Metabolomics: a tool for early detection of toxicological effects and an opportunity for biology based grouping of chemicals-from QSAR to QBAR. Mutation Research 746 144-150. (doi:10.1016/j.mrgentox.2012.01.006)

Robinson L, Gallos ID, Conner SJ, Rajkhowa M, Miller D, Lewis S, Kirkman-Brown J \& Coomarasamy A 2012 The effect of sperm DNA fragmentation on miscarriage rates: a systematic review and metaanalysis. Human Reproduction 27 2908-2917. (doi:10.1093/humrep/ des261)

Rockett JC, Patrizio P, Schmid JE, Hecht NB \& Dix DJ 2004 Gene expression patterns associated with infertility in humans and rodent models. Mutation Research 549 225-240. (doi:10.1016/j.mrfmmm. 2003.11.017)

Sanchez V, Redmann K, Wistuba J, Wubbeling F, Burger M, Oldenhof $\mathbf{H}$, Wolkers WF, Kliesch S, Schlatt S \& Mallidis C 2012 Oxidative DNA damage in human sperm can be detected by Raman microspectroscopy. Fertility and Sterility 98 1124-9e1-3. (doi:10.1016/j.fertnstert.2012. 07.1059)

Segerink LI, Sprenkels AJ, Oosterhuis GJE, Vermes I \& van den Berg A 2012 Lab-on-a-chip technology for clinical diagnostics: the fertility chip. Ned Tijdschr Klin Chem Labgeneesk 37 61-63.
Simon L, Lutton D, McManus J \& Lewis SE 2011 Sperm DNA damage measured by the alkaline Comet assay as an independent predictor of male infertility and in vitro fertilization success. Fertility and Sterility $\mathbf{9 5}$ 652-657. (doi:10.1016/j.fertnstert.2010.08.019)

Spiess AN, Feig C, Schulze W, Chalmel F, Cappallo-Obermann H, Primig M \& Kirchhoff C 2007 Cross-platform gene expression signature of human spermatogenic failure reveals inflammatory-like response. Human Reproduction 22 2936-2946. (doi:10.1093/humrep/dem292)

Tesarik J, Mendoza-Tesarik R \& Mendoza C 2006 Sperm nuclear DNA damage: update on the mechanism, diagnosis and treatment. Reproductive BioMedicine Online 12 715-721. (doi:10.1016/S14726483(10)61083-8)

Wang H, Zhou Z, Xu M, Li J, Xiao J, Xu ZY \& Sha J 2004 A spermatogenesisrelated gene expression profile in human spermatozoa and its potential clinical applications. Journal of Molecular Medicine 82 317-324. (doi:10.1007/s00109-004-0526-3)

World Health Organization 2010 WHO Laboratory Manual for the Examination and Processing of Human Semen. 5th edition. WHO Press. Geneva, Switzerland.

Wu W, Shen O, Qin Y, Niu X, Lu C, Xia Y, Song L, Wang S \& Wang X 2010 Idiopathic male infertility is strongly associated with aberrant promoter methylation of methylenetetrahydrofolate reductase (MTHFR). PLoS ONE 5 e13884. (doi:10.1371/journal.pone.0013884)

Yagci A, Murk W, Stronk J \& Huszar G 2010 Spermatozoa bound to solid state hyaluronic acid show chromatin structure with high DNA chain integrity: an acridine orange fluorescence study. Journal of Andrology 31 566-572. (doi:10.2164/jandrol.109.008912)

Yang B, Wang H, Gao XK, Chen BQ, Zhang YQ, Liu HL, Wang Y, Qin WJ, Qin RL, Shao GX et al. 2004 Expression and significance of Rap1A in testes of azoospermic subjects. Asian Journal of Andrology 6 35-40.

Zini A, Boman JM, Belzile E \& Ciampi A 2008 Sperm DNA damage is associated with an increased risk of pregnancy loss after IVF and ICSI: systematic review and meta-analysis. Human Reproduction 23 2663-2668. (doi:10.1093/humrep/den321)

Zylbersztejn DS, Andreoni C, Del Giudice PT, Spaine DM, Borsari L, Souza GH, Bertolla RP \& Fraietta R 2013 Proteomic analysis of seminal plasma in adolescents with and without varicocele. Fertility and Sterility 99 92-98. (doi:10.1016/j.fertnstert.2012.08.048)

Received 20 March 2013

First decision 7 May 2013

Revised manuscript received 20 August 2013

Accepted 23 September 2013 